\title{
"In the shoes of another": immersive technology for social and emotional learning
}

\author{
Marcus Cheng Chye $\operatorname{Tan}^{1}{ }^{1}$. Stefanie Yen Leng Chye ${ }^{1} \cdot K_{y l i n}$ Shu Min Teng ${ }^{1}$
}

Received: 2 July 2021 / Accepted: 2 February 2022 / Published online: 3 March 2022

(C) The Author(s), under exclusive licence to Springer Science+Business Media, LLC, part of Springer Nature 2022

\begin{abstract}
There has been increasing use of interactive technologies in the classroom today and a rising popularity of employing virtual environments as a means to engage students in sensorially rich contexts for more embodied forms of experiential learning. In particular, virtual reality (VR) or immersive virtual environments (IVEs) facilitated by head-mounted displays (HMDs) have been used in the teaching of subject content such as history, geography and science. This article presents the findings of an exploratory study of immersive technology, specifically immersive virtual environments (IVES), for the purpose of social and emotional learning (SEL), in the context of Character and Citizenship lessons in the Singapore classroom. The social and emotional competencies (SECs) examined in this project were specifically empathy and perspective-taking, and responsible decision-making. The study involved a sample of $n=75$ students from a cohort of students in a Singapore school, averaged at 15 years of age. Students were randomly divided into three treatment conditions: IVEs, pen-and-paper mental simulation and video-viewing. Each treatment contained a problem scenario, told from a first-person perspective, involving a social and ethical dilemma young people today face. A quasi-experimental, pretest post-test, non-equivalent group design was employed, and the study adopted a mixed-method approach to data collection. The findings reveal that IVEs are not necessarily more effective than the "pen-and-paper" and video viewing approaches to teaching SECs but they can better facilitate perspective-taking and empathy for a higher percentage of students.
\end{abstract}

Keywords Immersive virtual environment - Immersive technology · Social and emotional learning $\cdot$ Empathy $\cdot$ Perspective-taking $\cdot$ Responsible decision-making

Extended author information available on the last page of the article 


\section{Introduction}

Virtual Reality (VR) and IVEs are a trademark of the video game industry but its application outside of entertainment is now being realised. IVE's characteristic of being able to place the user "in the shoes of another" and assume another person's or avatar's perspective has encouraged educators to explore their pedagogical potential. In the U.K., students from St. Mary's College, Crosby learnt about the battlefields of World War One through a virtual recreation of these spaces, with students introduced to significant battles and battle sites via head-mounted displays (HMDs) (BBC News, 2017). Singapore's local broadsheet, The Straits Times, also featured the use of immersive virtual reality environments (IVREs) as a teaching tool for Social Studies in schools such as at West Spring Primary School (Tan, 2017). There have also been a greater number of studies on the effectiveness of IVEs in student learning performance. Liu et al. (2020)'s study involving sixth graders in a public school in the east region of China evidenced how students who learned via IVREs had better engagement with concepts than traditional teaching methods. Learning with IVREs led to students' improved understanding of scientific knowledge. This view is also shared by Yildirim et al. (2020) who surveyed STEM teachers on the use of VR as an alternative mode of teaching. Their study showed how VR captured students' interest, increased motivation and technology literacy, and helped teachers visualize abstract topics to improve instruction. Immersive technology has also been used for assistive learning, and virtual environments enable students to be more focussed by blocking out external distractions due to VR's immersive and interactive qualities (Zimmerman, 2019). Where teacher education is concerned, VR has been trialled for training teachers in classroom management skills (Lugrin et al., 2016).

This study responds to a local need for more creative, engaging and realistic ways of teaching SEL. Current modes of teaching SEL in Singapore, as part of the Character and Citizenship Education (CCE) curriculum, have not been particularly successful as they have been unable to facilitate the application of moral values in students (Tan \& Wong, 2010). With the increased use of information technology in the classroom today, and the rising popularity of virtual reality environments as a tool to engage students in sensorially rich contexts for more embodied forms of experiential learning, this exploratory project compares the effectiveness of IVEs with conventional modes of teaching such as video-viewing and pen-and-paper mental simulation. Given the younger generation of Singapore students who are digital natives, and are highly technologically-savvy and deeply acquainted with multi-sensorial stimulation as ways of acquiring skills or knowledge, the use of virtual reality or IVEs was a logical consideration to address the need for more engaging and novel pedagogical approaches to the teaching of SEL. The medium was also to be accompanied by realistic stories and identifiable protagonists such that current social issues could be effectively communicated. As there has been no sustained study on the use of IVEs in the Singapore classroom context, this project aimed to present preliminary findings about IVEs' effectiveness in facilitating greater empathy, perspective-taking and responsible decision-making. 


\subsection{Social and emotional learning in the Singapore classroom}

Education theorists and psychologists have posited the importance of the explicit teaching and inculcation of SECs as children with higher social-emotional skills do better in all aspects of study and life (Jones et al., 2015; Durlak et al., 2011). These include educational success, career success and achievement of life goals and outcomes. In Singapore, SEL has gained greater attention in the curriculum in the recent years particularly as the country's socio-economic dynamics have seen rapid change in the recent decade. Spurred by rapid technological change and cultural exchange, SEL has become more urgent and its competencies more imperative for students in negotiating a more socially complex society. Issues of racism and inequality have become pressing ones to address in the SEL classroom; the explicit teaching of SEL has thus become an urgent issue to address.

SEL is taught in schools as part of the CCE or Social Studies curriculum. The effectiveness of CCE in promoting active SEL teaching has however been limited. As explained by Kanagaratnam (2017), many teachers in Singapore do not see how values can be taught explicitly without making it come across as didactic and superficial. Furthermore, the ways in which it is taught lack authenticity and applicability to real-world situations, and the approaches are didactic and teacher-centred. (Kanagaratnam 2017).

In view of the need for more effective ways of teaching SEL, this study considered how IVEs can incorporate socially relevant, real-world problem scenarios, as an engaging and novel pedagogical approach. The use of authentic narratives framed as problem scenarios enable students to make independent choices based on careful thought and consideration, as opposed to a didactic approach. The first-person perspective in cinematic IVE facilitates the possibility of greater realism and deeper identification with the protagonist. As young Singapore students today are highly tech-savvy digital natives, we believed IVE would be an effective pedagogical tool for SEL teaching.

\subsection{IVEs impact on empathy, perspective-taking and responsible decision- making}

IVEs have been used to evaluate perspective-taking in previous studies (Shin, 2021; Ventura et al., 2021; Christofi, Michael-Grigoriou \& Kyrlitsias, 2020; Hamilton-Giachritsis et al., 2018; Ahn et al., 2016; Ahn, Le \& Bailenson, 2013). They are known to offer users more graphic and detailed visual information regarding their targets' perspectives (Ahn, Le \& Bailenson, 2013; Ahn et al., 2016) and this aids in users' imaginations (Oh et al., 2016) as it provides them with more realistic information regarding their targets' situations (Ahn, Le, \& Bailenson, 2013; Nilsson, Nordahl \& Serafin, 2016). IVEs can also make the perspective-taking process less effortful. According to Oh et al., IVE users may be less physically present in the physical world and more so in the virtual world. Consequently, they may feel less self-aware when involved in a perspective-taking exercise or imagining themselves in the targets' situation when compared to other modes such as mental simulation (Oh et al., 2016). This makes it easier for the IVE user to suppress his/her own perspective and take the perspective 
of his/her target (Chambers \& Davis, 2012). The diminished sense of physical presence is enhanced when IVE users view the situation from a first-person perspective. In these cases, IVEs eliminate the need for a virtual protagonist as it allows users to better imagine themselves as their targets (Elmezeny, Edenhofer \& Wimmer, 2018) through deeper experiences of embodying the protagonist.

Apart from perspective-taking, IVEs have also been positively associated with empathic development. Commonly touted as "empathy machines," IVEs facilitate the experience of events from others' perspectives (Milk, 2015; Thériault et al., 2021), and this can consequently generate empathy (Hamilton-Giachritsis et al., 2018; Herrera et al., 2018). IVEs can generate empathy in users as evidenced in many studies (Ahn et al., 2016; Oh et al., 2016; Bertrand et al., 2018; Herrera et al., 2018; Hamilton-Giachritsis et al., 2018; Shin, 2018; Wiederhold, 2020; Mado et al., 2021; Thériault et al., 2021; Ventura et al., 2021) and this is achieved by facilitating embodiment. Embodiment occurs when individuals feel as though they are experiencing events first-hand (Shin, 2018; Ahn, Le \& Bailenson, 2013), and it may even involve them perceiving that they are inhibiting the body of the protagonist, in more extreme cases; this is a phenomenon known as body transfer (Ahn et al., 2016; Mado et al., 2021; Slater et al., 2010; Kilteni et al., 2012; Wiederhold, 2020). Given that users can take their targets' perspectives through IVEs with relative ease for reasons mentioned earlier, and that perspective taking may result in experiencing greater empathy (Mado et al., 2021; Chambers \& Davis, 2012), IVE users may consequently experience higher levels of empathy for their targets, in comparison to other conventional modalities such as pen-and-paper mental simulation (Ventura et al., 2021, Herrera et al., 2018 and Oh et al., 2016). The positive effects that IVEs have on empathy consequently mean that IVEs can potentially be useful in moral education, particularly in terms of fostering concern for marginalized groups like racial minorities, transgender people, refugees, the homeless, and people with disabilities (Thériault et al., 2021; Mado et al., 2021; Christofi, Michael-Grigoriou \& Kyrlitsias, 2020; Rogers, 2020; Shin, 2018).

Both perspective-taking and empathy have been linked to responsible decisionmaking in prior research (Cojuharenco \& Sguera, 2015; Richardson et al., 1994; Oswald, 1996). Hence, the positive impact that IVE use has on perspective-taking and empathy can possibly have beneficial outcomes for teaching learners about responsible decision-making. Additionally, IVEs may also improve responsible decision-making through their ability to simulate situations that are difficult to observe first-hand or in person, such as ocean acidification and floods (Ahn et al., 2016). Previous research has found that most individuals tend to be less emotionally involved or engaged in situations that they are unable to observe directly or personally, and this could lead to them feeling a diminished sense of personal responsibility towards these matters (Uzzell, 2000). By being able to simulate situations that will otherwise be difficult to observe (Parsons \& Mitchell, 2002; Ahn et al., 2016; Francis et al., 2016; Ip et al., 2018), in a cost-effective manner (Ahn et al., 2016; Bertrand et al., 2018), IVEs can potentially increase the empathy and sense of personal responsibility users feel towards these issues, resulting in them becoming more committed to making positive behavioural changes in their daily lives (Ahn, 2015). Following this, several studies have found IVEs to be relatively successful in promoting ethical deci- 
sion making on a variety of different issues, ranging from prosocial helping behaviors towards the color blind (Ahn, Le \& Bailenson, 2013) and the homeless (Herrera et al., 2018; Mado et al., 2021), to environmental protection (Ahn, 2011) and financial planning (Sims, Bailenson \& Carstensen, 2015).

Additionally, there have been some studies on the use of IVE for the development of social-emotional skills in an education setting. These, however, have primarily looked at students with autism (Ip et al., 2018; Lorenzo et al., 2016; Cheng, Huang \& Yang, 2015; Ke \& Im, 2013; Lorenzo et al., 2013). These studies reveal how IVE users displayed improvements in their emotional competencies, thereby evidencing how such experiences via IVE are transferrable to real life situations (Lorenzo et al., 2016; Lorenzo et al., 2013). In Lorenzo et al. (2016)'s study, participants were able to transfer emotional competencies acquired during these sessions, which consisted of appropriate emotional responses to social situations which they were struggling with, to their school environments in real life. Teachers assessed these through monthly evaluations. Likewise, Lorenzo et al. (2013)'s study found that participants were able to transfer social competencies acquired during experimental sessions to school contexts, such as answering questions in class and preparing study materials needed for the following day. These findings demonstrate IVE's capacity to facilitate SEL in students' daily lives. Despite these encouraging findings, the use of IVEs in schools for SEL is still relatively new, and literature on the topic is scarce (Sandall, 2016). In fact, researchers are only just starting to uncover how SEL takes place in students, and how technology can be used to promote SEC development (Slov'ak et al. 2015a, 2015b). Our study addresses the need to provide further findings in this area particularly in relation to its effectiveness when compared to conventional ways of teaching SEL.

\section{Purpose and significance of study}

Our project employed IVEs facilitated by wearable HMDs to examine how such environments provide students opportunities for embodied empathy and perspectivetaking that subsequently influence their capacities for responsible decision-making. HMDs are effective platforms to facilitate immersive storytelling in a $360^{\circ}$ video environment (Elmezeny et al., 2018). It is important to distinguish immersive virtual environments (IVEs) from Immersive Virtual Reality Environments (IVREs). IVREs are digitally constructed spaces created by industrial computer graphics. These simulate navigable three-dimensional environments and allow users to be immersed in a virtual space. IVEs, on the other hand, include cinematic / photo-realistic environments. This distinction is necessary for this project employs cinematic IVE filmed from the first-person in a $360^{\circ}$ format. We chose to employ IVEs over IVREs as the research team desired a "true-to-life" experience not only in the narrative content but also in the visual experience.

The project sought to compare the use of IVEs with more conventional pedagogical approaches found in CCE lessons, specifically the viewing of a video or film extract (VID), and a pen-and-paper mental simulation exercise (P\&P). The research questions for this project were: Which modality (IVE, video-viewing, pen-and-paper 
mental simulation) is more effective in developing Social Awareness, specifically empathy, perspective-taking and responsible decision-making? Is immersive technology necessarily more effective than conventional approaches of teaching social-emotional competencies, i.e., pen-and-paper mental simulation and 2D video viewing?

Only SECs of perspective-taking, empathy and responsible decision-making were considered in this study as these were the most relevant aspects elicited by IVEs. Perspective-taking is understood as imagining oneself in the situation of another person (Batson et al., 1997; Ahn et al. 2016). It is the capacity to see things from the other person's viewpoint and can lead to the observer feeling as though $\mathrm{s} / \mathrm{he}$ shares a common identity with the target (Cialdini et al., 1997; Ahn, Le \& Bailenson, 2013). Empathy differs from perspective-taking in that it is affective in nature (Cuff et al., 2016). Specifically, the observer must experience emotions (Cuff et al., 2016), and these should be the same ones the target experiences (Singer \& Lamm, 2009). Empathy further involves the observer being aware that the emotion he is experiencing originates from the target, instead of himself (de Vignemont \& Singer, 2006). Frequently, empathy results from perspective-taking (Batson, 1991; de Waal, 2008); experiencing empathy and being able to take the perspective of another can then lead to responsible decision-making, in accordance with previous research (Oswald, 1996; Cojuharenco \& Sguera, 2015; Richardson et al., 1994). Here, responsible decision-making is defined as choosing to behave ethically both on a personal level and with others, while considering ethical and safety guidelines, social rules that govern behaviour, the potential implications of one's actions, as well as others' well-being (Durlak et al., 2011; Slovák \& Fitzpatrick, 2015). Responsible decision-making is generally based on core values (Harasym, Tsai \& Munshi, 2013) like benevolence, fairness, and respect for individuals.

Consequently, it was hypothesised that, in comparison to watching a 2D video or experiencing a pen-and-paper mental simulation, IVEs would facilitate stronger development in empathy and perspective-taking, which can then lead to more responsible decision-making.

\section{Methodology}

\subsection{Participants}

The research involved students at a Singapore school who were in their third year (IP3) of a six-year integrated programme. This would be equivalent to the third year of a 4-year secondary school education in Singapore. The student participants averaged at 15 years of age. This age group was selected because the brain regions in charge of perspective-taking have been documented to develop starting from the age of 15 (Davis \& Franzoi, 1991; Eisenberg et al., 2005). Since perspective-taking has been linked to both empathy and responsible decision-making (Oswald, 1996; Cojuharenco \& Sguera, 2015; Richardson et al., 1994), it would make sense for these brain developments to correspondingly lead to greater capacities for empathy and responsible decision-making as well. Hence, it is reasonable to conclude that indi- 
viduals of this age will be more responsive to efforts meant at increasing their SECs, including those put forth in this study.

IRB approval and informed consent from parents of the students were sought. There were 176 students in the entire IP3 cohort but only 76 gave informed consent (43.2\%). Of this number, $n=75$ students participated in the first session and $n=67$ students participated in the second. One student who provided informed consent was absent from both experimental sessions. Of the 75 students who attended the first experimental session, 8 did not attend the second session due to personal or schoolrelated commitments.

\subsection{Research design}

A quasi-experimental, pre-test post-test, non-equivalent group design was employed. In particular, 30 of the 76 participants who gave informed consent were randomly assigned to the IVE condition, with the remaining 46 participants being randomly and evenly split between VID and P\&P conditions (23 each). The larger number of participants allocated to the IVE condition was deemed to be necessary as IVE is a novel means of teaching SEL in schools (Sandall, 2016), especially when compared to VID and P\&P, both of which are conventional pedagogical approaches (Sim \& Print, 2005). Additionally, 30 participants were allotted the IVE condition as this is regarded to be the minimum number required for a large sample size (Hogg and Tanis, 2005; LaMorte, 2016). The effects of the treatment conditions were assessed based on a treatment-control group design in which participants in treatment and control groups were administered the same set of questionnaires four times: before each treatment and after each treatment.

\subsection{Procedure}

Each session was conducted as part of a regular CCE lesson of $60 \mathrm{~min}$. The principal investigators each took the lessons which involved the IVE and VID treatments, and a schoolteacher, assisted by the research assistant, taught the lesson which incorporated the P\&P treatment. For all treatments, and for both sessions, the topic of the lesson was introduced first, with this involving a general discussion with the class about the social issue that was to be presented in the treatment. Following this open discussion, participants took the pre-test. They were then introduced to the treatment, and this was followed by the post-test. The first session examined the topic of bullying faced by young Singaporeans today. The problem scenario depicted an incidence of bullying in school in which the protagonist experienced being physically harassed and victimised online. The second session looked at the prevalent subject of social and income inequality in Singapore, and so the problem scenario allowed participants to inhabit the role of a student, from a low-income family, who is faced with a dilemma of finding escort work to supplement the impoverished family's income. These topics are social issues currently debated in Singapore society, and particularly in schools. Both topics were decided by the participating School and the research team. In both instances, regardless of the treatment condition, the problem scenario ends in an open-ended fashion so participants can subsequently respond with solu- 
tions to the protagonists' dilemma. These scenarios, all presented from the first-person perspective, were identical for all three treatment conditions albeit presented in the three respective modalities: participants of the IVE treatment condition experienced the story from the perspective of the protagonist, in a photo-realistic immersive environment; the second group watched a video of the same story filmed from the protagonist's visual point-of-view; participants that experienced the last treatment read a narrative recount written by the protagonist.

\subsection{Data collection}

There were two data collection sessions, with a six-month gap between, to address possible threats to internal validity. This gap time also allowed for the elimination of other variables involving participants' immediate recall of their previous solution and accompanying emotions in the first experience, as well as discussions with peers which may influence responses to the second experience.

This study adopted a mixed-method approach to data collection, comprising of both quantitative and qualitative data. Quantitative measures included a pre and posttest self-report questionnaire to measure the SECs of empathy, perspective-taking and responsible decision-making. These questions were adaptations of Davis' (1980) "Interpersonal Reactivity Index" which is used to evaluate measures of empathy and perspective-taking. Additionally, survey items from Gehlbach, Brinkworth and Wang (2012)'s "Social Perspective Taking Propensity Scale" was used to help establish perspective-taking propensity. The adapted indexes showed any changes in participants' empathy levels and capacities to see another person's perspective. Scales and subscales from Zhou and Ee's (2012) "Social Emotional Competence Questionnaire (SECQ)" were also included to inform the survey questions on empathy, perspectivetaking and responsible decision-making. This questionnaire is contextually relevant as it is a questionnaire created by Singapore researchers to measure SECs in a Singapore context. Furthermore, the scale shows good internal consistency and predictive validity. The PCA results from our questionnaires confirmed that 4 distinct variables were being assessed, and that these variables have been reflected by the scales used to measure them. These variables are: Empathic Concern, Perspective Taking, Responsible Decision-Making and Presence. This indicates that the scales used in the questionnaires give accurate measurements of the variables they purport to measure, lending support to their use in the study. All the scales in the Pre-Tests and the Post-Tests administered to the students across both experimental sessions have either acceptable ( $>0.7)$ or preferable $(>0.8)$ Cronbach Alpha values, as defined by Julie Pallant (2013). This also affirms their reliability and suitability for use in our study.

The Pre-Test consisted of 19 questions that measured the extent participants engaged in empathy (Questions 1-7), perspective-taking (Questions 8-14), and responsible decision-making (Questions 15-19). The Post-Test consisted of the same, albeit with additional questions assessing the degrees of presence participants experienced (Questions 20-28). Specifically, 5 of the questions in each quantitative data questionnaire were reverse coded, which helped us to assess if the participants had read the questions before answering the questionnaires. In the quantitative questionnaire, with regards to perspective-taking, empathy, and responsible decision-making, 
participants rated how much they agreed with each statement on a 6-point Likert scale, with 1 point representing "Does not describe me well at all" and 6 points standing for "Very true of me".

The collection of the qualitative data happened in two ways. The post-test included Short-Answer Questions (SAQs) which required participants to respond to how they would attempt to resolve the problem presented in the scenario, to evaluate responsible decision-making. It also had questions that evaluated presence, immersion and embodiment with these being adaptations from Witmer and Singer (1998) and Ahn (2011). To support findings from the short-answer questionnaire, interviews were conducted with selected participants based on purposive sampling methods (Patton, 2015). The interviews sought more detailed responses to questions about perspectivetaking and empathy in relation to the treatment conditions and how the treatment impacted their selected solution to the problem scenario. Interviewees were selected based on their written responses to the SAQs, specifically on the impact of their intervention experiences on the competencies. Participants' intervention experiences could have impacted SECs in 3 different ways - an increase, no notable change, or a decrease in levels. Participants' SAQ responses were then correspondingly coded, using Content Analysis, to determine the types of impact their intervention experiences had on SEC development. Only participants who indicated similar outcomes, across both scenarios, based on the respective interventions were selected. For example, a student who indicated that IVE had a positive effect on his/her SEC development for only the first experimental session but not for the second would not be selected as an interviewee. This served to minimize the effects of different scenarios on interviewees' SEC development and ensured that the stated impacts were due to the interventions. In total, 22 participants were invited to participate in the interviews but only $7(31.8 \%)$ consented. Interviews were conducted by a member of the research team. In view of the Covid-19 situation, each interviewee had a choice of having a face-to-face interview or an online interview. Each interview lasted for about 50 min on average. Table 1 showcases the key interview questions that participants were asked.

Table 1 Key interview questions on the three SECs

\begin{tabular}{ll}
\hline SEC & Interview Question \\
\hline Perspective-Taking & $\begin{array}{l}\text { Did the medium / technology help } \\
\text { you to assume the protagonist's per- } \\
\text { spective better? How? Why? }\end{array}$ \\
& $\begin{array}{l}\text { Did the medium / technology help } \\
\text { you to empathise with the protagonist } \\
\text { Empathy }\end{array}$ \\
& $\begin{array}{l}\text { better? How? Why? } \\
\text { Could you explain what prompted you }\end{array}$ \\
to arrive at the solution you provided \\
Decision-Making & $\begin{array}{l}\text { in your response to the task? What } \\
\text { role, if any, did the technology play? }\end{array}$ \\
\hline
\end{tabular}




\subsection{Quantitative data analysis}

The quantitative data analysis examined SEC development for each experimental session independently, which allowed for the possibility that the interventions' abilities to facilitate student SEC development may differ depending on the scenario used.

MANOVA was deemed to be suitable for the analysis given that it involved multiple dependent variables (DVs). The three SECs examined in this study - perspectivetaking, empathy and responsible decision-making - served as the DVs. Specifically, repeated measures MANOVA was the statistical technique of choice as SEC development (Post-Test - Pre-Test) was repeatedly measured at multiple points in time. SEC development was examined for each experimental session, whereupon a different scenario was used (i.e., scenario one was used for experimental session one and scenario two was used for experimental session two). The independent variables (IVs) for the repeated measures MANOVA consisted of the intervention (BetweenSubjects IV) and the scenario (Within-Subjects IV) respectively.

Despite Wilks' Lambda $(\Lambda)$ being more commonly used in research, the use of Pillai's Trace (V) for quantitative data interpretation has been recommended in the case of certain issues arising with the data, such as the presence of a small sample size, or that of unequal N values across experimental conditions (Pallant, 2013). Since the quantitative dataset for this study only consisted of 66 participants, and different numbers of participants were present across the three experimental conditions (IVE: 26; VID: 18; P\&P: 22), these issues were applicable to the current dataset, and the case to use Pillai's Trace over Wilks' Lambda justified. As such, Pillai's Trace was used to interpret the quantitative data for this study.

There were three missing values in the dataset. Data Imputation, specifically, Expectation-Maximization (EM) Imputation was employed to deal with these three missing values, in line with Twisk \& de Vente (2002)'s and Scheffer (2002)'s recommendations for repeated Measures MANOVAs and SPSS respectively. With the three missing values imputed as $2.56,2.83$ and 0.34 , the assumption of no missing values for repeated Measures MANOVAs (Verma, 2016) was met. As rounding the imputations may lead to inaccuracies in the results obtained (Wu, Jia \& Enders, 2015), the three imputed values were retained and not rounded to their closest Likert scale values.

Two very small univariate outliers $(\mathrm{z}=3.35$ for perspective-taking; $\mathrm{z}=-3.49$ for responsible decision-making) were found in the dataset for the first session, as defined by $z$ scores $= \pm 3.29, p<0.001$ (Tabachnick \& Fidel, 2013). Due to the limited sample size, these univariate outliers were retained in the dataset to prevent data loss.

Considering that the research question entailed examining if IVE was more effective in facilitating SEC development compared to VID and P\&P, planned comparisons, involving one-way-ANOVAs (Verma, 2016) were also conducted for the quantitative data analysis. This is in addition to the two-way repeated measures MANOVA. Specifically, two kinds of planned comparisons involving IVE were carried out - the first contrasted IVE with VID, and the second contrasted IVE with P\&P. Overall, twelve planned comparisons were performed for the quantitative data analysis: 3 DVs x 2 Scenarios x 2 kinds of planned comparisons. Even though several 
planned comparisons were carried out in the study, the alpha level for each of them was maintained at 0.05, in line with Pagano (2013)'s recommendation.

As only comparisons involving IVE were planned for prior to conducting this study, post hoc tests contrasting VID's and P\&P's abilities to facilitate SEC development were further conducted. 'Tukey' was the post hoc test of choice for this study, as per Verma (2016)'s and Stevens (2009)'s recommendations for data analyses concerning repeated measures. Following Verma (2016)'s suggestion, Bonferroni Adjustments were carried out for the post hoc tests, whereby the alpha level of 0.05 was divided by the number of unique post hoc tests conducted. As three unique 'Tukey' post hoc tests contrasting VID and P\&P were conducted for this study, the alpha level used for each test, after Bonferroni Adjustments, was $0.05 \div 3=0.0167$ (3s.f.).

\subsection{Qualitative data analysis}

Participants who were present for at least one experimental session had their SAQ responses analysed, whereas participants who gave consistent responses across both scenarios were interviewed. Both the SAQ responses and interview data were analyzed using Content Analysis, one of the most frequently used approaches of analyzing qualitative data in research (Silverman, 2014). Following this method, we formulated sets of categories, or codes, based on the data and recorded the number of participants who raised comments for each category. We also made efforts to safeguard both the validity and reliability of the qualitative data analysis during the coding process. For instance, the validity of the coding process was established through maintaining exact counts of the participants' responses (Silverman, 2014). In line with Hammersley (1992)'s recommendations, reliability was further established by having the same researcher code the same set of data multiple times and checking it for consistency (intra-rater reliability). In the case of discrepancies, another researcher was brought in to code the data (Syed \& Nelson, 2015).

Percent agreement, a popular measure of reliability (De Wever et al., 2006), was selected as a measure of intra-rater reliability for Content Analysis conducted due to its ease of computation and how it can be used for both ordinal and nominal coding categories (Syed \& Nelson, 2015), both of which were present for our study. Despite percent agreement being a liberal measure of reliability, it can still serve as a wholly sufficient measure of reliability in research (Syed \& Nelson, 2015). This means that percent agreement can be used as a standalone measure of reliability for Content Analysis without the need to use it in conjunction with other means of establishing reliability. The overall percent agreement for the qualitative data analyses was $88.9 \%$, which falls within the $80 \%$ benchmark agreed upon by researchers for Content Analysis (Columbia Mailman School of Public Health, 2019; Neuendorf, 2002).

In addition, for both experimental sessions, the number of participants who indicated that they experienced perspective-taking and empathy in their written responses for the SAQs was recorded and converted into percentages. These percentages were also averaged across scenarios to develop an overall understanding of IVE's effectiveness in facilitating perspective-taking and empathy, as seen in Figs. 2 and 3. The percentages of participants who made responsible and irresponsible decisions were in turn determined by coding participants' written solutions to the scenarios using 
Content Analysis. This was done to identify the different types of solutions participants came up with, as well as the specific percentage of participants who decided to engage in these.

\section{Results and findings}

\subsection{Quantitative findings}

The Interaction Effect (between the two IVs, Intervention and Scenario) for the twoway repeated measures MANOVA was not statistically significant for overall SEC development, $F(6,124)=1.348, p=0.241, V=0.122, \eta^{2}=0.061$. This means that the interventions were as effective in facilitating overall SEC development for scenario one as they were for scenario two, and that the type of scenario used did not make a difference in the interventions' abilities to facilitate overall SEC development.

The Interaction Effect was also not statistically significant for the three specific SECs: for perspective-taking, $F(2,63)=2.493, p=0.091, \eta^{2}=0.073$; empathy, $F(2$, $63)=1.181, p=0.314, \eta^{2}=0.036$; and responsible decision-making, $F(2,63)=0.178$, $\mathrm{p}=0.837, \eta^{2}=0.006$. This suggests that the interventions were as effective in facilitating perspective-taking, empathy, and responsible decision-making for both scenarios. The type of scenario used also did not make a difference in the interventions' abilities to facilitate perspective-taking, empathy, or responsible decision-making.

Since the Interaction Effect was not statistically significant, both for overall SEC development and for the three specific SECs, the Main Effect of Intervention was examined. The Main Effect of Scenario was not studied as it was deemed to be less relevant to our research purposes.

The Main Effect of Intervention was not statistically significant as well. Examining both experimental sessions, participants from all three experimental conditions did not differ significantly in terms of overall levels of SEC development, $\mathrm{F}(6,124)=0.533, \mathrm{p}=0.782, \mathrm{~V}=0.050, \eta^{2}=0.025$; or when it comes to their levels of perspective-taking, $\mathrm{F}(2,63)=0.434, \mathrm{p}=0.650, \eta^{2}=0.014$; empathy, $\mathrm{F}(2,63)=0.804$,

Table 2 Table of results for the two-way repeated measures MANOVA

\begin{tabular}{lllllll}
\hline Effect & $\begin{array}{l}\text { Aspect of SEC Development } \\
\text { Involved }\end{array}$ & $\begin{array}{l}\text { De- } \\
\text { grees of } \\
\text { Freedom } \\
(\mathrm{df})\end{array}$ & $\begin{array}{l}\mathrm{F} \\
\text { Value } \\
(\mathrm{F})\end{array}$ & $\begin{array}{l}\text { Significance } \\
(\mathrm{p}) \text { (Alpha } \\
\text { level=0.05) }\end{array}$ & $\begin{array}{l}\text { Pillai's } \\
\text { Trace } \\
(\mathrm{V})\end{array}$ & $\begin{array}{l}\text { Partial } \\
\text { Eta } \\
\text { Squared } \\
\left(\eta^{2}\right)\end{array}$ \\
\hline Interaction & Overall SEC Development & $\mathrm{F}(6,124)$ & 1.348 & $\mathbf{0 . 2 4 1}$ & 0.122 & 0.061 \\
Effect & Perspective-Taking & $\mathrm{F}(2,63)$ & 2.493 & $\mathbf{0 . 0 9 1}$ & N.A. & 0.073 \\
& Empathy & & 1.181 & $\mathbf{0 . 3 1 4}$ & N.A. & 0.036 \\
& Responsible Decision-Making & & 0.178 & $\mathbf{0 . 8 3 7}$ & N.A. & 0.006 \\
Main Effect of & Overall SEC Development & $\mathrm{F}(6,124)$ & 0.533 & $\mathbf{0 . 7 8 2}$ & 0.050 & 0.025 \\
Intervention & Perspective-Taking & $\mathrm{F}(2,63)$ & 0.434 & $\mathbf{0 . 6 5 0}$ & N.A. & 0.014 \\
& Empathy & & 0.804 & $\mathbf{0 . 4 5 2}$ & N.A. & 0.025 \\
& Responsible Decision-Making & & 0.554 & $\mathbf{0 . 5 7 7}$ & N.A. & 0.017 \\
\hline
\end{tabular}


$\mathrm{p}=0.452, \eta^{2}=0.025$; and responsible decision-making, $\mathrm{F}(2,63)=0.554, \mathrm{p}=0.577$, $\eta^{2}=0.017$

Refer to Table 2 for a table of results detailing the effects examined for the twoway repeated measures MANOVA i.e., The Interaction Effect and the Main Effect of Intervention.

The planned comparisons, involving one-way ANOVAs and IVE, revealed a significant difference between the impact of IVE and P\&P on participants' perspectivetaking levels for scenario two, $\mathrm{t}(63)=-2.111, \mathrm{p}=0.039$. Specifically, those in the $\mathrm{P} \& \mathrm{P}$ condition $(\mathrm{M}=0.169, \mathrm{SD}=0.278)$ recorded higher levels of perspective-taking than those in the IVE condition $(\mathrm{M}=-0.033, \mathrm{SD}=0.351)$ on average; a statistically significant difference of 0.202 points. The other planned comparisons, including the ones contrasting IVE with VID, were not statistically significant, whereby $p>0.05$.

Table 3 Table of results for all planned comparisons involving IVE

\begin{tabular}{llllll}
\hline SEC & Scenario & $\begin{array}{l}\text { Type of Planned } \\
\text { Comparison } \\
\text { Conducted }\end{array}$ & $\begin{array}{l}\text { Degrees of } \\
\text { Freedom } \\
(\mathrm{df})\end{array}$ & T Value (t) & $\begin{array}{l}\text { Signifi- } \\
\text { cance }(\mathrm{p}) \\
(\alpha=0.05)\end{array}$ \\
\hline Perspective-Taking & One & IVE vs. VID & $\mathrm{t}(63)$ & 1.106 & $\mathbf{0 . 2 7 3}$ \\
& & IVE vs. P\&P & & 0.906 & $\mathbf{0 . 3 6 8}$ \\
& \multirow{2}{*}{ Two } & IVE vs. VID & & -0.875 & $\mathbf{0 . 3 8 5}$ \\
& & IVE vs. P\&P & & -2.111 & $\mathbf{0 . 0 3 9 *}$ \\
Empathy & One & IVE vs. VID & & -1.713 & $\mathbf{0 . 0 9 2}$ \\
& & IVE vs. P\&P & & -0.125 & $\mathbf{0 . 9 0 1}$ \\
& Two & IVE vs. VID & & -0.277 & $\mathbf{0 . 7 8 3}$ \\
Responsible & & IVE vs. P\&P & & -0.694 & $\mathbf{0 . 4 9 0}$ \\
Decision-Making & One & IVE vs. VID & & -0.556 & $\mathbf{0 . 5 8 1}$ \\
& & IVE vs. P\&P & & -0.762 & $\mathbf{0 . 4 4 9}$ \\
& Two & IVE vs. VID & & 0.187 & $\mathbf{0 . 8 5 3}$ \\
& & IVE vs. P\&P & & -0.808 & $\mathbf{0 . 4 2 2}$ \\
\hline
\end{tabular}

* Statistically significant at $\alpha=0.05$

Fig. 1 Graph and descriptive statistics on the statistically significant planned comparison involving IVE and P\&P (Perspective-Taking, scenario two)

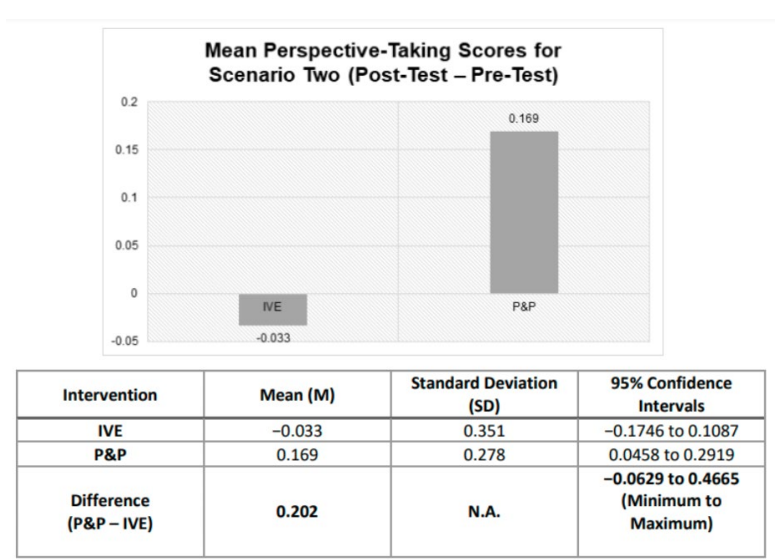


Fig. 2 Percentage of participants who indicated that they had engaged in perspective-taking

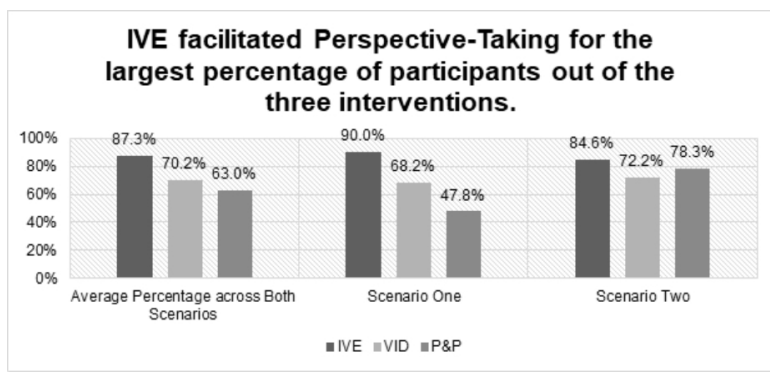

Fig. 3 Percentage of participants who indicated that they had experienced empathy

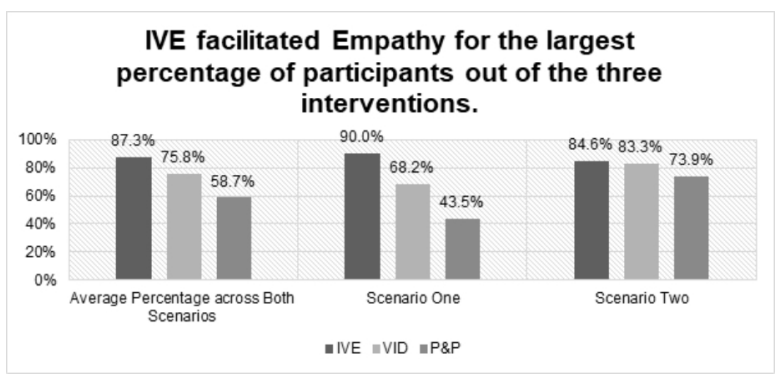

Table 3; Fig. 1 below show the full set of results for the planned comparisons conducted for this study.

The post hoc tests contrasting VID with P\&P were further shown to not be statistically significant for all three SECs, where $\mathrm{p}>0.0167$, evidencing how VID and P\&P did not differ significantly in their impact on participants' SEC levels. Table 4 below shows the results of the post hoc tests conducted for this study.

As P\&P was the only intervention to have recorded higher levels of SEC development on a statistically significant level in this study, $\mathrm{P} \& \mathrm{P}$ is, correspondingly, the most effective intervention of the three examined in terms of facilitating higher levels of SEC development.

\subsection{Qualitative findings}

Participants' SAQ responses revealed that IVE had managed to facilitate perspectivetaking for the largest proportion of participants of the three interventions in both scenario one (on bullying), and scenario two (on inequality). This makes IVE the most effective intervention in terms of facilitating perspective-taking for a larger per-

Table 4 Table of results for all Tukey post hoc tests contrasting VID with $\mathrm{P} \& \mathrm{P}$

\begin{tabular}{llll}
\hline SEC & $\begin{array}{l}\text { Nature of } \\
\text { Post Hoc } \\
\text { Tests }\end{array}$ & $\begin{array}{l}\text { Mean } \\
\text { Difference } \\
(\mathrm{i}-\mathrm{ii})\end{array}$ & $\begin{array}{l}\text { Signifi- } \\
\text { cance }(\mathrm{p}) \\
(\alpha=0.0167)\end{array}$ \\
\hline Perspective-Taking & (i) VID & -0.0707 & $\mathbf{0 . 6 5 9}$ \\
Empathy & vs. (ii) & 0.0740 & $\mathbf{0 . 7 4 1}$ \\
Responsible & P\&P & -0.0702 & $\mathbf{0 . 8 0 2}$ \\
Decision-Making & & & \\
\hline
\end{tabular}


centage of participants. The percentage of participants who indicated that they had experienced perspective-taking in both scenarios, as well as on average, is displayed in Fig. 2 below.

Likewise, IVE managed to facilitate empathy for the largest proportion of participants for both scenarios, making IVE the most effective intervention where facilitating empathy was concerned. The percentage of participants who indicated that they had experienced empathy in both scenarios, as well as on average, are presented in Fig. 3 below.

In contrast, $\mathrm{P} \& \mathrm{P}$ seems to the most effective intervention in facilitating responsible decision-making, with participants who experienced the P\&P condition being the

Fig. 4 Percentage of participants who made the responsible decision to help other victims of bullying

Fig. 5 Percentage of participants who made the irresponsible decision to engage in retaliation strategies

Fig. 6 Percentage of participants who made the responsible decision not to become a social escort
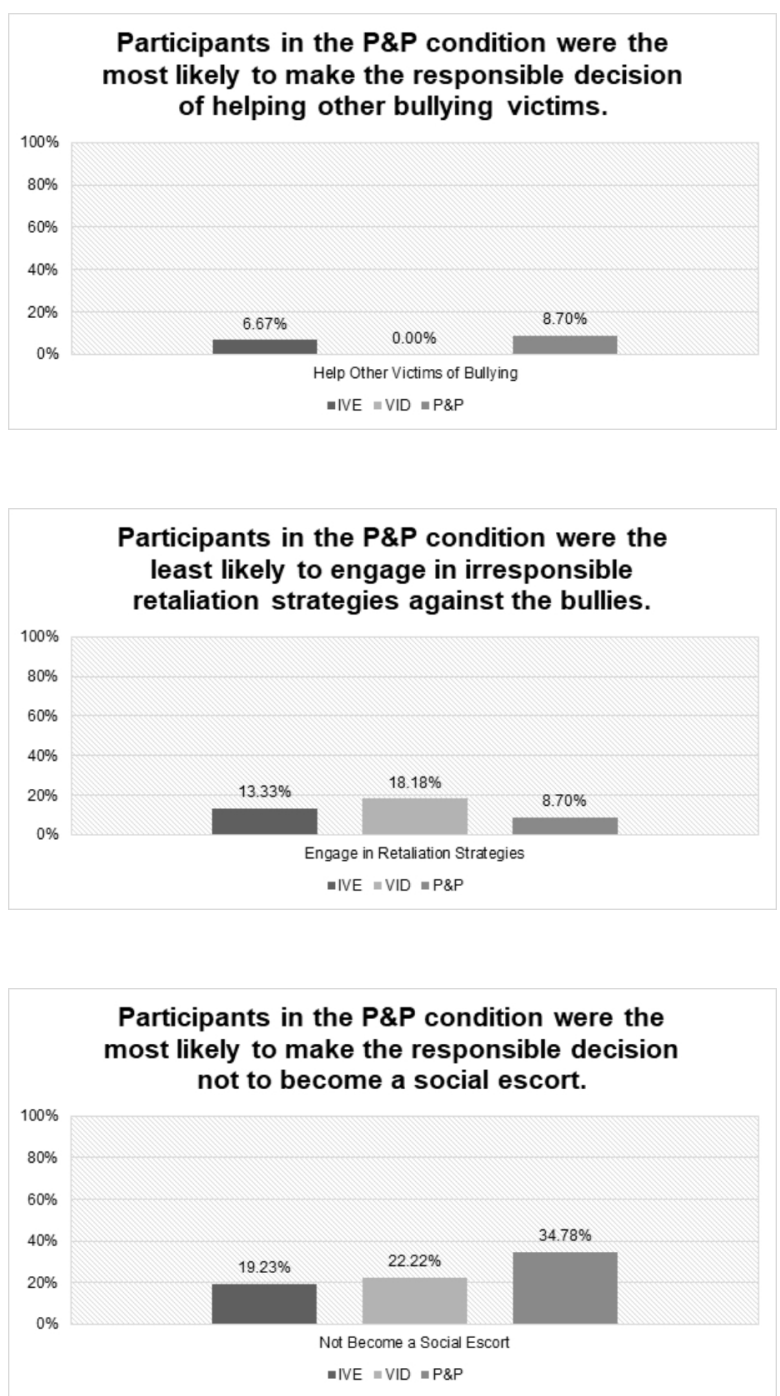
most likely to make responsible decisions and the least likely to make irresponsible ones in both scenarios. For scenario one, for example, participants who experienced P\&P were the most likely to make the responsible decision to help other victims of bullying, and the least likely to engage in irresponsible retaliation strategies (i.e., fight back or take revenge) against the bullies. Figures 4 and 5 show the percentage of participants who made the aforementioned decisions in scenario one.

Similarly, for scenario two, participants in the P\&P condition were the most likely to make the responsible decision to not become a social escort and the least likely to make the less responsible decision to become a social escort. Figures 6 and 7 show the percentage of participants who made these decisions in scenario two.

The interviews provided further insight into IVE's capacity to promote perspective-taking and empathy for a larger segment of participants. According to participant IVE-25, IVE's ability to provide more visual information about one's surroundings and the plot led to stronger feelings of immersion. In response to an interview question on the degree of immersion, participant IVE-25 replied, "you get to see, like, everything you would see in real life. Like, even the more minor, minor details they included in it, I think, like the video, the VR... [These minor details include] the items on the table [in scenario two]." These details provided a strong sense of immersion. IVE's ability in providing visual information led to participants having a better understanding of the protagonists' situation through active perspective-taking that consequently led to empathy with the protagonists' experiences. IVE-25 explains, "you understand the surroundings better and [consequently] the living situation [the protagonist was in]." As immersion has been linked to perspective-taking and empathy in this study, affirming prior research (Herrera et al., 2018), it is logical to deduce that IVE's capacity for visual detail, and the higher degrees of immersion this results in, has contributed to its success in facilitating perspective-taking and empathy.

Although P\&P's ability to facilitate responsible decision-making for a larger percentage of participants seemingly contradicts previous research, which has shown IVE to be more effective than mental simulation (Ahn, 2011; Ahn, Le \& Bailenson, 2013; Herrera et al., 2018), the interview data suggests a possible reconciliation to these two findings. Specifically, responsible decision-making includes both the making of ethical choices, as well as acting upon these choices (Durlak et. al, 2011; Ministry of Education, Singapore, 2012). As mentioned above, participants' SAQ responses revealed that $\mathrm{P} \& \mathrm{P}$ participants were more likely to make responsible

Fig. 7 Percentage of participants who made the less responsible decision to become a social escort

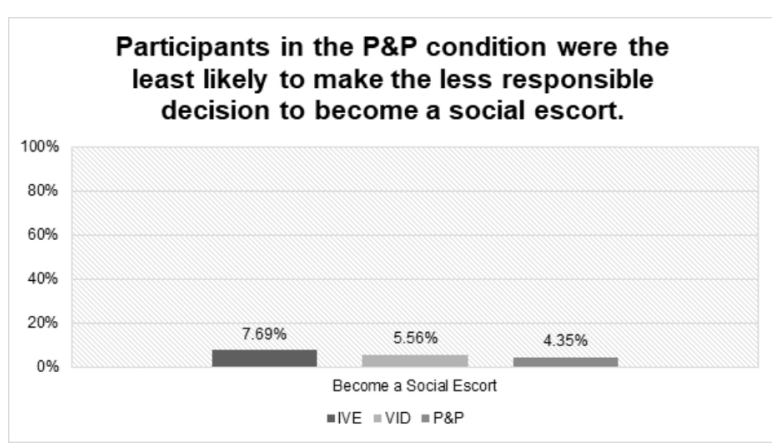


choices for both scenarios (see Fig. 4 to 7). The interview data, alternatively, shows that IVE can motivate helpful behaviours in participants. IVE aids this by generating empathy for the protagonist thereby motivating participants to take helpful actions. As participant IVE-6 states, "if their [participants'] emotions are aroused, then they can actually go ahead to move forward and help [others]." Considering that greater motivation to help others does result in helping behaviours in real life (Weinstein \& Ryan, 2010), the increased motivation to aid others that participants in the IVE condition experienced may consequently translate to actual helping behaviours. While $\mathrm{P} \& \mathrm{P}$ seems more successful in encouraging a greater proportion of participants to make responsible decisions, IVE complements with the possibility of translating participants' responsible decisions to actual, real-life helping behaviours. Collectively, these findings suggest that IVE and P\&P may be effective at facilitating different aspects of responsible decision-making, and that their potential impact in facilitating responsible decision-making is complementary. Certainly, future research is necessary to verify these hypotheses.

\section{Discussion}

This study aimed to assess the effectiveness of IVEs in developing perspective-taking, empathy and responsible decision-making, in comparison to more conventional modes of teaching SEL. In particular, the qualitative data reveals how IVE has greater impact on perspective-taking and empathy in that it encourages these SECs in a larger proportion of participants. This affirms our hypothesis and existing studies that examine IVE's impact of assuming the perspective of another and engendering empathic responses (Ahn et al., 2016; Shin, 2018; Herrera et al., 2018). The qualitative data also reveals that IVEs lent to greater immersion, a deeper sense of presence, and embodiment, since these are the key characteristics (and strengths) of IVEs. Notably, our study has revealed links among these three concepts - between immersion and presence, between presence and embodiment, as well as between embodiment and SEC development; specifically, the development of perspective-taking and empathy - all of which align with previous literature on these topics (Biocca, 2003; Baños et al., 2004; Borrego et al., 2019; Ahn, Le \& Bailenson, 2013; Ahn et al., 2016; Shin, 2018; Herrera et al., 2018). Our study confirms that, by generating greater immersion, IVEs also generate higher levels of presence and embodiment; this has positive impact on perspective-taking and empathy.

Yet, while IVE appears to have more success in encouraging perspective-taking and empathy for a larger percentage of participants, P\&P seems to be more effective in facilitating higher levels of perspective-taking, at least with scenario two. P\&P is also able to facilitate responsible decision-making for a greater percentage of participants. Examination of participants' SAQ responses reveal that this could be due to P\&P's descriptive nature, its informativeness, specifically regarding the protagonist's thoughts and feelings, and its ability to facilitate deeper reflection regarding problem resolution. This is contrary to the team's initial hypothesis that IVE would be the medium that encourages positive responsible decision-making given that it facilitates greater degrees of perspective-taking and empathy; it was assumed that the capacity 
to effectively assume another person's perspective would encourage deeper empathy and so allow one to make more responsible decisions. This study calls into question that assumption possibly because emotional distance from the dilemma, predicament or problem is what allows one to make more rational decisions, as opposed to the emotional involvement that may result from stronger perspective-taking and deeper empathy. Such a view is affirmed by the SAQ responses, in which participants mentioned that P\&P's capacity for greater detachment from situations - in other words, less emotional involvement - contributed to their ability to make better decisions.

Considering that IVE and P\&P may have positive impact on different aspects of SEL, their use seems complementary. This suggests that IVE can be used with P\&P to facilitate more effective SEL. Doing so will possibly result in a larger proportion of participants engaging in all three SECs, accompanied by higher levels of perspective-taking.

Additional insights can be gleaned from these results. For instance, given that perspective-taking has been linked to responsible decision-making in previous research (Cojuharenco \& Sguera, 2015; Richardson et al., 1994), the higher levels of perspective-taking $\mathrm{P} \& \mathrm{P}$ facilitated consequently contributed to responsible decision-making for a greater percentage of participants. Also, despite promoting both perspective-taking and empathy for a larger segment of participants, IVE was not better at facilitating responsible decision-making. Hence, generating higher levels of perspective-taking seems to be more helpful in facilitating responsible decision-making, which is what $\mathrm{P} \& \mathrm{P}$ achieved. This differs from how IVE encourages perspectivetaking and empathy for a larger percentage of participants.

Using IVE to teach SEL may, however, present some problems to participants. Firstly, IVE's inability to allow participants to independently visualize storyline events could potentially cause it to be less able to encourage creativity and responsible decision-making, in comparison to P\&P. Additionally, as revealed in the interviews, users reported facing a few issues because of their IVE experiences, including dizziness. These issues have in turn resulted in even more negative outcomes for them, like a reduced ability to comprehend the narrative content shown. This can negatively impact the medium's capacity to allow perspective-taking and empathy due to a reduced sense of immersion, presence and embodiment. However, overall, our qualitative findings reveal that IVE still presents as an effective means of facilitating perspective-taking and empathy for a greater segment of participants.

\section{Limitations \& future research}

One of the most significant limitations of this study was the low participation rate of students. The research team had anticipated that $90 \%$ of the student cohort would participate in the study, but only $43.2 \%$ provided consent. Low rates of consent from the students and the corresponding limited sample size meant that two very small univariate outliers had to be retained in the quantitative data to prevent data loss. Furthermore, due to the small number of respondents, certain information may not have been captured in the qualitative data, resulting in it being less comprehensive. Hence, the results of this study may be less generalizable to the larger student popu- 
lation in Singapore. Future studies on this subject should thus ideally be conducted with larger participant samples to increase the generalizability of results. Also, participants in this study may not fully represent Singapore's student population: This study's participating school is recognized as among the top schools in Singapore that admits more academically inclined students. Thus, the students who took part in this study may be more interested in and better able to learn from reading texts than students across Singapore's student population. Hence, the results of this study, where P\&P managed to facilitate higher levels of perspective-taking in participants for scenario two, as well as facilitate responsible decision-making for the largest percentage of participants of the three interventions, may not be generalizable to Singapore's student population. Future studies should involve participants from a range of schools so as to be more representative of Singapore's student population. These studies will consequently be useful in ascertaining P\&P's effectiveness in facilitating SEC development. Finally, considering that this was a small-scale exploratory project, another pedagogical approach of teaching SEL in the Singapore classroom was not considered in the treatment comparison. Arts-based or drama-based approaches, such as role-playing or an enactment of a short skit, are at times used by some teachers as embodied learning practices in CCE lessons. Research has shown that dramatic approaches can be an effective teaching tool for the teaching and learning of SEL (Usakli, 2018; Joronen et al., 2011; Valdes, 2019). For example, drama-based pedagogies have been used to build social-emotional capacities in children with dyslexia in Singapore (Hamzah, 2019). Like IVEs, drama approaches such as role-playing can place students in another person's shoes to facilitate perspective-taking and even encourage the development of empathy. A future development of this project, as such, could be a comparative study of the effectiveness of drama-based approaches and IVEs in the teaching of SEL, given both methods facilitate opportunities for embodied perspectives and experiences.

Funding This project was funded by the Ministry of Education, Singapore, Education Research Funding Programme.

Data availability Data is available on reasonable request.

\section{Declarations}

Ethics approval IRB approval was given by Nanyang Technological University Institutional Review Board, IRB-2019-04-027-01.

Consent to participate A written informed consent form was provided to the participants and their parents / guardians, asking for giving consent for voluntary participation and informing about the guarantee of anonymity and confidentiality. This was signed by all participants.

Conflict of interest The authors declare no conflicts of interest. 


\section{References}

Ahn, S. J. (2011). Embodied experiences in immersive virtual environments: Effects on pro-environmental attitude and behavior. Stanford, California, USA: Stanford University. Retrieved from http://citeseerx.ist.psu.edu/viewdoc/download?doi=10.1.1.363.6152\&rep=rep1\&type=pdf

Ahn, S. J., Le, A. M. T., \& Bailenson, J. (2013). The effect of embodied experiences on self-other merging, attitude, and helping behavior. Media Psychology, 16(1), 7-38. https://doi.org/10.1080/15213269.2 012.755877

Ahn, S. J. (2015). Incorporating immersive virtual environments in health promotion campaigns: A construal level theory approach. Health communication, 30(6), 545-556. https://doi.org/10.1080/10410 236.2013.869650

Ahn, S. J. G., Bostick, J., Ogle, E., Nowak, K. L., McGillicuddy, K., \& Bailenson, J. (2016). Experiencing nature: embodying animals in immersive virtual environments increases inclusion of nature in self and involvement with nature. Journal of Computer-Mediated Communication, 21(6), 399-419. https://doi.org/10.1111/jcc4.12173

Batson, C. D., Polycarpou, M. P., Harmon-Jones, E., Imhoff, H. J., Mitchener, E. C., Bednar, L. L. ... Highberger, L. (1997). Empathy and attitudes: Can feeling for a member of a stigmatized group improve feelings toward the group? Journal of personality and social psychology, 72(1), 105-118. https://doi.org/10.1037/0022-3514.72.1.105

Batson, C., \& Daniel (1991). The Altruism Question: Toward a Social-Psychological Answer. New York, USA: Psychology Press

BBC News (2017). Bringing WW1 battlefields to life with virtual reality. BBC. 27 March 2017. https:// www.bbc.com/news/av/education-39388422. Accessed 18 May 2021

Bertrand, P., Guegan, J., Robieux, L., McCall, C., \& Zenasni, F. (2018). Learning empathy through virtual reality: Multiple strategies for training empathy-related abilities using body ownership illusions in embodied virtual reality. Frontiers in Robotics and AI, 5(26), 1-18. https://doi.org/10.3389/ frobt.2018.00026

Biocca, F. (2003). Can we resolve the book, the physical reality, and the dream state problems? From the two-pole to a three-pole model of shifts in presence. In EU Future and Emerging Technologies, Presence Initiative Meeting, 12, 13-69. Retrieved from https://citeseerx.ist.psu.edu/viewdoc/download?d $\mathrm{oi}=10.1 \cdot 1.545 .7706 \& \mathrm{rep}=\mathrm{rep} 1 \&$ type $=\mathrm{pdf}$

Baños, R. M., Botella, C., Alcañiz, M., Liaño, V., Guerrero, B., \& Rey, B. (2004). Immersion and emotion: their impact on the sense of presence. Cyberpsychology \& Behavior, 7(6), 734-741. https://doi. org/10.1089/cpb.2004.7.734

Borrego, A., Latorre, J., Alcañiz, M., \& Llorens, R. (2019). Embodiment and presence in virtual reality after stroke. A comparative study with healthy subjects. Frontiers in neurology, 10, 1061-1068. https://doi.org/10.3389/fneur.2019.01061

Chambers, J. R., \& Davis, M. H. (2012). The role of the self in perspective-taking and empathy: Ease of self-simulation as a heuristic for inferring empathic feelings. Social Cognition, 30(2), 153-180. https://doi.org/10.1521/soco.2012.30.2.153

Cheng, Y., Huang, C. L., \& Yang, C. S. (2015). Using a 3D immersive virtual environment system to enhance social understanding and social skills for children with autism spectrum disorders. Focus Autism on Other Developmental Disabilities, 30(4), 222-236. https://doi.org/10.1177/1088357615583473

Christofi, M., Michael-Grigoriou, D., \& Kyrlitsias, C. (2020). A virtual reality simulation of drug users' everyday life: the effect of supported sensorimotor contingencies on empathy. Frontiers in Psychology, 11(1242), 6-17. https://doi.org/10.3389/fpsyg.2020.01242

Cialdini, R. B., Brown, S. L., Lewis, B. P., Luce, C., \& Neuberg, S. L. (1997). Reinterpreting the empathy-altruism relationship: When one into one equals oneness. Journal of Personality and Social Psychology, 73(3), 481-494. https://doi.org/10.1037/0022-3514.73.3.481

Cojuharenco, I., \& Sguera, F. (2015). When empathic concern and perspective taking matter for ethical judgment: The role of time hurriedness. Journal of Business Ethics, 130(3), 717-725. https://doi. org/10.1007/s10551-014-2259-8

Columbia University Mailman School of Public Health (2019). Content Analysis. Columbia University Mailman School of Public Health. Retrieved from https://www.publichealth.columbia.edu/research/ population-health-methods/content-analysis

Cuff, B. M., Brown, S. J., Taylor, L., \& Howat, D. J. (2016). Empathy: A review of the concept. Emotion Review, 8(2), 144-153. https://doi.org/10.1177/1754073914558466 
Davis, M. H. (1980). A multidimensional approach to individual differences in empathy. Catalog of Selected Documents in Psychology, 10, 85-103. Retrieved from https://www.uv.es/friasnav/Davis_1980.pdf

Davis, M. H., \& Franzoi, S. L. (1991). Stability and change in adolescent self-consciousness and empathy. Journal of research in Personality, 25(1), 70-87. https://doi.org/10.1016/0092-6566(91)90006-c

De Vignemont, F., \& Singer, T. (2006). The empathic brain: how, when and why? Trends in Cognitive Sciences, 10(10), 435-441. https://doi.org/10.1016/j.tics.2006.08.008

De Waal, F. B. (2008). Putting the altruism back into altruism: the evolution of empathy. Annual Review of Psychology, 59(1), 279-300. https://doi.org/10.1146/annurev.psych.59.103006.093625

De Wever, B., Schellens, T., Valcke, M., \& Van Keer, H. (2006). Content analysis schemes to analyze transcripts of online asynchronous discussion groups: A review. Computers \& education, 46(1), 6-28. https://doi.org/10.1016/j.compedu.2005.04.005

Durlak, J. A., Weissberg, R. P., Dymnicki, A. B., Taylor, R. D., \& Schellinger, K. B. (2011). The impact of enhancing students' social and emotional learning: a meta-analysis of school-based universal interventions. Child Development, 82(1), 405-432. https://doi.org/10.1111/j.1467-8624.2010.01564.x

Eisenberg, N., Cumberland, A., Guthrie, I. K., Murphy, B. C., \& Shepard, S. A. (2005). Age changes in prosocial responding and moral reasoning in adolescence and early adulthood. Journal of research on adolescence, 15(3), 235-260. https://doi.org/10.1111/j.1532-7795.2005.00095.x

Elmezeny, A., Edenhofer, N., \& Wimmer, J. (2018). Immersive storytelling in 360-Degree videos: an analysis of interplay between narrative and technical immersion. Journal of Virtual Worlds Research, 11(1), 1-13. https://doi.org/10.4101/jvwr.v11i1.7298

Francis, K. B., Howard, C., Howard, I. S., Gummerum, M., Ganis, G., Anderson, G., et al. (2016). Virtual Morality: Transitioning from Moral Judgment to Moral Action? PLoS ONE, 11(10), e0164374. https://doi.org/10.1371/journal.pone.0164374

Gehlbach, H., Brinkworth, M. E., \& Wang, M. T. (2012). The social perspective taking process: What motivates individuals to take another's perspective?. Teachers College Record, 114(1), 197-225. Retrieved from https://dash.harvard.edu/bitstream/handle/1/11393841/Gehlbach\%20SPTMotivations.pdf? sequence $=1$

Hamilton-Giachritsis, C., Banakou, D., Quiroga, M. G., Giachritsis, C., \& Slater, M. (2018). Reducing risk and improving maternal perspective-taking and empathy using virtual embodiment. Scientific Reports, 8(1), 1-10. https://doi.org/10.1038/s41598-018-21036-2

Hammersley, M. (1992). Research and Policy. Lewes, East Sussex, England: Falmer Press

Hamzah, M. (2019). An evaluation of the effectiveness of using drama as a tool to build social-emotional development of children with dyslexia in Singapore. Asia Pacific Journal of Developmental Differences, 6(1), 127-149. Retrieved from https://das.org.sg/images/publications/apjdd/apjddjan2019/ APJDD-Vol6-No1.pdf\#page $=133$

Harasym, P. H., Tsai, T. C., \& Munshi, F. M. (2013). Is problem-based learning an ideal format for developing ethical decision skills? The Kaohsiung Journal of Medical Sciences, 29(10), 523-529. https:// doi.org/10.1016/j.kjms.2013.05.005

Herrera, F., Bailenson, J., Weisz, E., Ogle, E., \& Zaki, J. (2018). Building long-term empathy: A largescale comparison of traditional and virtual reality perspective-taking. PloS ONE, 13(10), e0204494. https://doi.org/10.1371/journal.pone.0204494

Hogg, R. V., \& Tanis, E. A. (2005). Probability and Statistical Inference (7th ed.). Upper Saddle River, New Jersey: Pearson/Prentice Hall

Ip, H. H., Wong, S. W., Chan, D. F., Byrne, J., Li, C., Yuan, V. S. ... Wong, J. Y. (2018). Enhance emotional and social adaptation skills for children with autism spectrum disorder: A virtual reality enabled approach. Computers \& Education, 117, 1-15. https://doi.org/10.1016/j.compedu.2017.09.010

Oswald, P. A. (1996). The effects of cognitive and affective perspective taking on empathic concern and altruistic helping. The Journal of social psychology, 136(5), 613-623. https://doi.org/10.1080/0022 4545.1996.9714045

Oh, S. Y., Bailenson, J., Weisz, E., \& Zaki, J. (2016). Virtually old: Embodied perspective taking and the reduction of ageism under threat. Computers in Human Behaviour, 60, 398-410. https://doi. org/10.1016/j.chb.2016.02.007 
Pagano, R. R. (2013). Understanding Statistics in the Behavioral Sciences (10th ed.). Wadsworth, Cengage Learning

Pallant, J. (2013). SPSS survival guide (5th ed.). New South Wales: Allen \& Unwin: Crow's Nest

Parsons, S., \& Mitchell, P. (2002). The potential of virtual reality in social skills training for people with autistic spectrum disorders. Journal of intellectual disability research, 46(5), 430-443. https://doi. org/10.1046/j.1365-2788.2002.00425.x

Patton, M. Q. (2015). Qualitative evaluation and research methods (4th ed.). Newbury Park: Sage

Jones, D. E., Greenberg, M., \& Crowley, M. (2015). Early social-emotional functioning and public health: the relationship between kindergarten social competence and future wellness. American Journal of Public Health, 105(11), 2283-2290. https://doi.org/10.2105/ajph.2015.302630

Joronen, K., Hämkämies, A., \& Åstedt-Kurki, P. (2011). Children's experiences of a drama programme in social and emotional learning. Scandinavian Journal of Caring Sciences, 25, 671-678. https://doi. org/10.1111/j.1471-6712.2011.00877

Kanagaratnam, T. (2017). Character \& citizenship education: what's the point?. Character \& Citizenship Education, Ministry of Education

Ke, F., \& Im, T. (2013). Virtual-reality-based social interaction training for children with high-functioning autism. The Journal of Educational Research, 106(6), 441-461. https://doi.org/10.1080/00220671. 2013.832999

Kilteni, K., Groten, R., \& Slater, M. (2012). The sense of embodiment in virtual reality. Presence: Teleoperators and Virtual Environments, 21(4), 373-387. https://doi.org/10.1162/pres_a_00124

LaMorte, W. W. (2016). The role of probability. Central Limit Theorem. Retrieved from https://sphweb. bumc.bu.edu/otlt/mph-modules/bs/bs704 probability/BS704 Probability12.html

Liu, R., Wang, L., Lei, J., Wang., Q., \& Ren, Y. (2020). Effects of an immersive virtual reality-based classroom on students' learning performance in science lessons. British Journal of Educational Technology, 51(5), 2034-2049. https://doi.org/10.1111/bjet.13028

Lorenzo, G., Pomares, J., \& Lledó, A. (2013). Inclusion of immersive virtual learning environments and visual control systems to support the learning of students with Asperger syndrome. Computers \& Education, 62, 88-101. https://doi.org/10.1016/j.compedu.2012.10.028

Lorenzo, G., Lledó, A., Pomares, J., \& Roig, R. (2016). Design and application of an immersive virtual reality system to enhance emotional skills for children with autism spectrum disorders. Computers \& Education, 98, 192-205. https://doi.org/10.1016/j.compedu.2016.03.018

Lugrin, J. L., Latoschik, M. E., Habel, M., Roth, D., Seufert, D., \& Grafe, S. (2016). Breaking bad behaviors: a new tool for learning classroom management using virtual reality. Frontiers in ICT, 3(26), 1-21. https://doi.org/10.3389/fict.2016.00026

Mado, M., Herrera, F., Nowak, K., \& Bailenson, J. (2021). Effect of Virtual Reality Perspective-Taking on Related and Unrelated Contexts. Cyberpsychology, Behavior, and Social Networking. https://doi. org/10.1089/cyber.2020.0802

Milk, C. (2015). How virtual reality can create the ultimate empathy machine. TED: Ideas worth spreading. Retrieved from https://www.ted.com/talks/ chris_milk_how_virtual_reality_can_create_the_ultimate_empathy_machine

Nilsson, N. C., Nordahl, R., \& Serafin, S. (2016). Immersion Revisited: A review of existing definitions of immersion and their relation to different theories of presence. Human Technology, 12(2), 108-134. https://doi.org/10.17011/ht/urn.201611174652

Ministry of Education, Singapore (2012). 2014 Syllabus character and citizenship education (secondary).

Neuendorf, K. A. (2002). The content analysis guidebook. Thousand Oaks, California, USA: SAGE Publications

Richardson, D. R., Hammock, G. S., Smith, S. M., Gardner, W., \& Signo, M. (1994). Empathy as a cognitive inhibitor of interpersonal aggression. Aggressive behavior, 20(4), 275-289. https://oi. org/10.1002/1098-2337(1994)20:4<275::aid-ab2480200402>3.0.co;2-4

Rogers, S. (2020). Virtual Reality For Good Use Cases: From Educating On Racial Bias To Pain Relief During Childbirth. Forbes. Retrieved from https://www.forbes.com/sites/solrogers/2020/03/09/virtual-reality-for-good-use-cases-from-educating-on-racial-bias-to-pain-relief-during-childbirth/?sh= $2714084163 \mathrm{f5}$

Sandall, B. K. (2016). Wearable technology and schools: where are we and where do we go from here?. Journal of Curriculum, Teaching, Learning and Leadership in Education, 1(1), 74-83. Retrieved from https://digitalcommons.unomaha.edu/cgi/viewcontent.cgi?article=1009\&context=ctlle 
Scheffer, J. (2002). Dealing with missing data, Research Letters in the Information and Mathematical Sciences, 3, 153-160. Retrieved from https://mro.massey.ac.nz/bitstream/handle/10179/4355/Dealing_with_Missing_Data.pdf

Shin, D. (2018). Empathy and embodied experience in virtual environment: To what extent can virtual reality stimulate empathy and embodied experience? Computers in Human Behavior, 78, 64-73. https://doi.org/10.1016/j.chb.2017.09.012

Shin, D. B. (2021). Exploring the Role of Virtual Reality Perspective Taking on Teachers' Cognitive Empathy: An Action Research Study. Dissertations, Theses, and Masters Projects. The College of William \& Mary. Paper 1627407556. Retrieved from https://scholarworks.wm.edu/cgi/viewcontent. cgi? article $=7150 \&$ context $=$ etd

Sim, J. B. Y., \& Print, M. (2005). Citizenship education and social studies in Singapore: A national agenda. International Journal of Citizenship and Teacher Education, 1(1), 58-73. Retrieved from https:// citeseerx.ist.psu.edu/viewdoc/download?doi=10.1.1.487.2707\&rep=rep1\&type=pdf

Sims, T., Bailenson, J., \& Carstensen, L. L. (2015, November). Connecting to your future self: Enhancing financial planning among diverse communities using virtual technology. GERONTOLOGIST, 5(2), 311-311. https://doi.org/10.1093/geront/gnv610.04

Silverman, D. (2014). Interpreting qualitative data. Methods for Analyzing Talk, Text and Interaction. London: SAGE Publications

Singer, T., \& Lamm, C. (2009). The social neuroscience of empathy. Annals of the New York Academy of Sciences, 1156(1), 81-96. https://doi.org/10.1111/j.1749-6632.2009.04418.x

Slater, M., Spanlang, B., \& Corominas, D. (2010). Simulating virtual environments within virtual environments as the basis for a psychophysics of presence. ACM Transactions on Graphics (TOG), 29(4), 1-9. https://doi.org/10.1145/1833349.1778829

Slov'ak, P., \& Fitzpatrick, G. (2015). Teaching and developing social and emotional skills with technology. ACM Transactions on Computer-Human Interaction, 22(4), 19-34. https://doi.org/10.1145/2744195

Slov'ak, P., Gilad-Bachrach, R., \& Fitzpatrick, G. (2015a, April). Designing Social and Emotional Skills Training: The Challenges and Opportunities for Technology Support. In Proceedings of the 33rd Annual ACM Conference on Human Factors in Computing Systems. Association for Computing Machinery, 2797-2800. https://doi.org/10.1145/2702123.2702385

Slov'ak, P., Thieme, A., Murphy, D., Tennent, P., Olivier, P., \& Fitzpatrick, G. (2015b, February). On Becoming a Counsellor: Challenges and Opportunities to Support Interpersonal Skills Training. In Proceedings of the 18th ACM Conference on Computer Supported Cooperative Work \& Social Computing. Association for Computing Machinery, 1336-1347. https://doi.org/10.1145/2675133.2675190

Stevens, J. P. (2009). Applied multivariate statistics for the social sciences (5th ed.). New York, USA

Syed, M., \& Nelson, S. C. (2015). Guidelines for establishing reliability when coding narrative data. Emerging Adulthood, 3(6), 375-387. https://doi.org/10.31234/osf.io/scu9x

Tabachnick, B. G., \& Fidell, L. S. (2013). Using Multivariate Statistics (6th ed.). Boston, MA: Pearson

Tan, C., \& Wong, Y. L. (2010). Moral Education for Young People in Singapore: Philosophy, Policy andProspects. Journal of Youth Studies, 13(2), 89-102

Tan, W. (2017). School excursions become a virtual reality for primary school pupils. The Straits Times. 23 May 2017. https://www.straitstimes.com/singapore/school-excursions-become-a-virtual-reality-forprimary-school-pupils. Accessed 18 May 2021

Thériault, R., Olson, J. A., Krol, S. A., \& Raz, A. (2021). Body Swapping with a Black Person Boosts Empathy: Using Virtual Reality to Embody Another. Quarterly Journal of Experimental Psychology, 74(12), 2057-2074. https://doi.org/10.1177/17470218211024826

Twisk, J., \& de Vente, W. (2002). Attrition in longitudinal studies: how to deal with missing data. Journal of clinical epidemiology, 55(4), 329-337. https://doi.org/10.1016/S0895-4356(01)00476-0

Uzzell, D. L. (2000). The psycho-spatial dimension of global environmental problems. Journal of environmental psychology, 20(4), 307-318. https://doi.org/10.1006/jevp.2000.0175

Usakli, H. (2018). Drama based social emotional learning. Global Research in Higher Education, 1(1), 1-16. https://doi.org/10.22158/grhe.v1n1p1

Valdes, K. S. (2019). Humanizing the classroom: using role-plays to teach social and emotional skills in Middle School and High School. Lanham, Maryland: Rowman \& Littlefield

Ventura, S., Cardenas, G., Miragall, M., Riva, G., \& Baños, R. (2021). How Does It Feel to Be a Woman Victim of Sexual Harassment? The Effect of $360^{\circ}$-Video-Based Virtual Reality on Empathy and Related Variables. Cyberpsychology, Behavior, and Social Networking, 24(4), 258-266. https://doi. org/10.1089/cyber.2020.0209 
Verma, J. P. (2016). Repeated measures design for empirical researchers. Hoboken, New Jersey: John Wiley \& Sons

Wiederhold, B. K. (2020). Embodiment Empowers Empathy in Virtual Reality. Cyberpsychology. Behavior and Social Networking, 23(11), 725-726. https://doi.org/10.1089/cyber.2020.29199.editorial

Weinstein, N., \& Ryan, R. M. (2010). When helping helps: autonomous motivation for prosocial behavior and its influence on well-being for the helper and recipient. Journal of personality and social psychology, 98(2), 222-244. https://doi.org/10.1037/a0016984

Witmer, B. G., \& Singer, J. M. (1998). Measuring presence in virtual environments: A presence questionnaire. Presence: Teleoperators and Virtual Environments, 7, 225-240. https://doi. org/10.1162/105474698565686

Wu, W., Jia, F., \& Enders, C. (2015). A comparison of imputation strategies for ordinal missing data on Likert scale variables. Multivariate Behavioral Research, 50(5), 484-503. https://doi.org/10.1080/0 0273171.2015 .1022644

Yildirim, B., Sahin-Topalcengiz, E., Arikan, G., \& Timur, S. (2020). Using virtual reality in the classroom: reflections of STEM teachers on the use of teaching and learning Tools. Journal of Education in Science, Environment and Health, 6(3), 231-245. https://doi.org/10.21891/jeseh.711779. Accessed 18 May 2021

Zhou, M., \& Ee, J. (2012). Social Emotional Competence Questionnaire. The International Journal of Emotional Education, 4(2), 27-42. https://doi.org/10.1037/t69172-000

Zimmerman, E. (2019). AR/VR in K-12: Schools use immersive technology for assistive learning. EdTech: Focus on K-12. 22 August 2019. Retrieved from https://edtechmagazine.com/k12/article/2019/08/ arvr-k-12-schools-use-immersive-technology-assistive-learning-perfcon

Publisher's note Springer Nature remains neutral with regard to jurisdictional claims in published maps and institutional affiliations.

\title{
Authors and Affiliations
}

\section{Marcus Cheng Chye Tan ${ }^{1} \cdot$ Stefanie Yen Leng Chye ${ }^{1} \cdot$ Kylin Shu Min Teng ${ }^{1}$}

\author{
Marcus Cheng Chye Tan \\ marcus.tan@nie.edu.sg \\ Stefanie Yen Leng Chye \\ stefanie.chye@nie.edu.sg \\ Kylin Shu Min Teng \\ shumin.teng@nie.edu.sg \\ 1 National Institute of Education, Nanyang Technological University, 1 Nanyang Walk, \\ 637616 Singapore, Singapore
}

